\title{
0 poder, a comunicação e o diálogo no ambiente organizacional
}

\section{Sandra Helena Terciotti}

- Doutora e Mestra em Letras (Literatura Portuguesa) pela Universidade de São Paulo

- Professora Assistente e Coordenadora do Programa de Nivelamento em Português e Matemática do Centro Universitário FECAP

- Coordenadora e Mediadora dos Encontros Literários e Assessora da Pró-Reitoria de Extensão e Desenvolvimento do Centro Universitário FECAP

- Professora de Comunicação Empresarial e Português Instrumental, respectivamente, dos cursos de Administração de Empresas e Ciências Contábeis do Centro Universitário FECAP

- Experiência em desenvolvimento de disciplinas em EAD (Comunicação Empresarial; Português Instrumental - FECAP-SP; Produção e Planejamento de Cursos em EAD SENAC-DN) e tutoria (EAD na Prática - COGEAE-PUC-SP)

- Experiência na área de Letras, com ênfase em Literatura Portuguesa, bem como nas áreas de Literatura Portuguesa Contemporânea, Literatura Brasileira, Teoria da Literatura, Língua Portuguesa, Português Instrumental, Técnicas de Redação e Comunicação Empresarial

- Autora do livro Comunicação Empresarial na Prática (2009)

- sandra.terciotti@tarra.com.br 
Neste artigo, analisaremos as interfaces existentes entre o poder, a linguagem, a cultura, a comunicação e o diálogo nas organizações. Investigaremos ainda os motivos que subjazem à interdição da fala no ambiente organizacional e as vantagens de uma gestão fundada na comunicação e no diálogo e que, por consequência, seja participativa, visando o desenvolvimento da organização sem, todavia, deixar de lado o indivíduo.

PALAVRAS-CHAVE: PODER • LINGUAGEM • CULTURA • COMUNICAÇÃO • DIÁLOGO • ORGANIZAÇÃO

\section{Abstract}

In this article we will analyze the interfaces between power, language, culture, communication and dialogue in the organizations. We will also investigate the reasons underlying the ban on speaking in the organizational environment, as well as the advantages of management based on communication and dialogue, and that, as a consequence, is participatory, aiming at development of the organization, yet without leaving aside the individual.

KEYWORDS: POWER • LANGUAGE • CULTURE • COMMUNICATION • DIALOGUE • ORGANIZATION

Resumen

Se analizan las interfaces existentes entre el poder, el lenguaje, la cultura, la comunicación y el diálogo en las organizaciones. Se investigan también los motivos que subyacen a la prohibición del habla en el ambiente organizacional y las ventajas de una gestión basada en la comunicación y en el diálogo y que, en consecuencia, sea participativa, con el objetivo de promover el desarrollo de la organización sin dejar de lado al individuo.

PALABRAS CLAVE: PODER • LENGUAJE • CULTURA • COMUNICACIÓN • DIÁLOGO • ORGANIZACIÓN 


\section{0 poder nas organizações}

$\mathrm{N}$ Dicionário eletrônico Houaiss da língua portuguesa, a décima oitava acepção do verbete "poder" define-o como "supremacia em dirigir e governar as ações de outrem pela imposição da obediência; dominação, domínio”. Desde os primórdios, o homem tem verdadeira compulsão pelo poder. A história da humanidade revela que o homem sempre esteve em busca do poder. Mesmo as sociedades tribais já possuíam instrumentos de poder. A família, menor célula social, reproduz a hierarquização do poder. Na relação marido e mulher, por exemplo, o uso do poder por um dos cônjuges sobre o outro é uma forma de compensar a insegurança pessoal daquele que o exerce. A Igreja também não escapa do recurso ao poder. Totalmente hierarquizada, ela reproduz a práxis do capitalismo no qual o poder, centrado no capital e relacionado ao "ter", é a palavra de ordem. A própria sala de aula, apesar de socializante, não deixa de reproduzir a hierarquização do poder, e essa hierarquização acentuase ainda mais quando a distância física entre os alunos e o professor e entre os próprios alunos for do tipo "sociofugal" (FREITAS, 2005), ou seja, do tipo militar, com carteiras dispostas em colunas e linhas, rejeitando ou dificultando a interatividade.

Como vemos, a busca incessante do homem pelo poder sempre esteve presente através dos tempos e sob as mais diversas formas. Essa onipresença do poder revela-nos que, além de ser uma necessidade social, ele é inerente ao homem. Mais do que estrutura de autoridade, o poder é uma relação instrumental entre pessoas, mais precisamente entre líderes e liderados. Para Adler e Rodman, o poder pode ser definido "como a capacidade de liderar os outros" (ADLER; RODMAN, 2003, p. 217). Sidinéia Gomes Freitas concorda com essa proposição ao afirmar que "a liderança influencia e, talvez por esta razão, é vista e analisada como sinônimo de poder" (FREITAS, 2006, p. 142). O exercício do poder e da influência pode dar-se de várias maneiras, indo da liberdade de escolha à coerção ou coação dos liderados, ou seja, à anulação do poder do outro. No entanto, por mais democráticas e sutis que nos possam parecer, as relações de poder entre líderes e liderados são relações de dominação que se baseiam no poder de barganha. A identificação (comprometimento provocado pelo magnetismo do líder), a internalização (comprometimento total), a socialização (instrução), a coopção (ou adaptação) e a mortificação constituem exemplos de relações de dominação e visam mudanças de atitude e não de comportamento. Relativamente à mortificação, Sidinéia Gomes Freitas faz a seguinte afirmação: "A mortificação fortalece a identificação. Por exemplo, estagiários alvos de sátiras de funcionários estáveis acabarão por identificar-se e aliar-se às normas vigentes" (FREITAS, 2006, p. 143).

Em seu artigo "Poder, Linguagem e Ação nas Organizações", Stewart Clegg (2007) afirma que falar em organização significa necessariamente falar em poder, pois este é parte essencial da realidade organizacional e jamais deixará de sê-lo. No âmbito organizacional, o poder e a influência do líder advêm da 
combinação entre magnetismo pessoal e conhecimento, e a maior ou menor descentralização de poder está ligada ao número de atores que desempenham as ações, ou seja: poucas mãos remetem a uma baixa distribuição de poder, enquanto muitas mãos remetem a uma alta distribuição de poder, o que não significa ausência, mas descentralização de poder.

Além dessa espécie de simbiose entre organização e poder, devemos considerar que, no bojo de toda e qualquer organização, existe uma dialética entre poder e resistência, já que tanto o dominador quanto o dominado atuam nas relações de poder, embora a culpa geralmente recaia sobre o dominador. Como o poder gera o contrapoder, para impedir a ascensão deste, os líderes estabelecem regras ou as chamadas "práticas disciplinares", abordadas por Foucault e Weber, que designam "as microtécnicas de poder que estabelecem e regulamentam não apenas os indivíduos, mas também a coletividade” (CLEGG, 2007, p. 51). Essas práticas disciplinares podem constituir-se em mecanismos de controle do tipo pessoal, técnico, burocrático ou jurídico e visam exercer o poder sobre o comportamento, as disposições e a integração dos empregados da organização. Quando diretas e pessoais, elas podem não só invadir, mas também pôr fim à privacidade dos empregados.

Toda organização que se pretende eficaz necessita implantar algumas práticas disciplinares globais. Essa implementação ocorre porque, além de constituírem mecanismos de controle, tais práticas reforçam e possibilitam o desejo de obediência e submissão e são formas reconhecidas de produtividade graças às estratégias de controle explícitas (regras) e implícitas (aceitação por parte do grupo). Para Clegg, "a resistência a controles formais está presente em todo processo fundamentado em práticas disciplinares num contexto hierárquico" (2007, p. 53), pois os elos dos níveis hierárquicos raramente são passivos. Ou seja, se por um lado as organizações facultam aos que estão em posição de autoridade um poder facilitador, por outro lado, são minadas pela criatividade dos empregados que acabam por encontrar uma maneira de se beneficiarem das relações simbólicas. Além disso, por demandarem interpretação, as regras ou práticas disciplinares paradoxalmente levam à inovação e à negociação por parte dos liderados. Isso significa que, por mais práticas disciplinares que possa haver numa organização, o poder nunca é garantido, pois sempre está subordinado à ação dos sujeitos que constituem os objetos desse poder. Daí a importância da ação estratégica, que constitui uma tentativa de determinar a interpretação e de estabelecer ações que defendam os interesses organizacionais em jogo. Daí também a preferência, cada vez mais acentuada nos dias atuais, pela contratação de gestores jovens que, pela própria inexperiência, não questionam nem desafiam a hierarquia da estrutura organizacional. Aliás, a prática de contratar profissionais mais jovens, além de assegurar a obediência à autoridade, constitui uma das situações que, segundo Maria Ester de Freitas, "geram fortes vulnerabilidades entre indivíduos e grupos, institucionalizam a guerra interna, reforçam as ambiguidades e inseguranças sobre o empregado e adubam o terreno para a ação de predadores organizacionais” (2007, p. 74). 
Outro impeditivo para a garantia de poder é o fato de o poder implicar necessariamente delegação de responsabilidades. Essa delegação torna o poderoso (o líder), dependente da obediência do delegado (o liderado), pois não há como garantir ou controlar a ação daquele a quem o poder da ação é delegado, senão por meio da sua lealdade.

Stewart Clegg (2007) afirma ainda que o indivíduo é visto pelas organizações de duas formas: na teoria e na ação social, como ator simbólico, e na teoria radical, como produtor. Como o indivíduo é, ao mesmo tempo, mão-de-obra e identidade social definida pela etnia, idade, cultura e pelo gênero, a subjetividade resultante dessa identidade social limita a ação da organização. Por isso, a questão das relações de poder dentro de uma organização deve considerar não só as relações de produção, mas também as relações simbólicas, já que o poder interfere na hierarquia, na linguagem, na dominação (poder) e no simbólico (discurso/saber). Para Clegg, essas "relações simbólicas são tão resistentes ao poder como as relações de produção" (2007, p. 54). O simbólico e o corpo, ligados aos indivíduos, são formas "de resistência ao poder organizacional que pode ser exercido simultaneamente sobre os discursos dos indivíduos e sobre suas capacidades de trabalho" (CLEGG, 2007, p. 54). E a única forma de os empregadores conseguirem controlar as capacidades discursivas (simbólicas) e físicas (ação) de seus funcionários é por meio da disciplina e da relação contratual formal, relação que também constitui uma tentativa de conciliar as relações simbólicas com as relações de produção.

Como vimos até aqui, "o poder exprime-se nas e pelas práticas disciplinares e pelas lutas que se opõem ou resistem a tais práticas” (CLEGG, 2007, p. 65). As organizações funcionam, portanto, como uma espécie de teatro em que são exercidos poderes multiformes, tangíveis (recursos humanos, financeiros, tecnológicos etc.) e intangíveis (conhecimento, informação etc.), e não um poder único e absoluto. O poder é uma forma de comunicação, e esta, por sua vez, também se constitui numa fonte e num instrumento de poder, já que "o poder, a organização e a ação exprimem-se invariavelmente nas políticas simbólicas e em sua interpretação" (CLEGG, 2007, p. 66). Não é, portanto, à toa que a imprensa é frequentemente chamada de "quarto poder". Nas organizações, a comunicação eficaz facilita as relações de poder, ao passo que a ineficaz dificulta-as. Além disso, justamente por constituir-se em fonte e instrumento de poder, a comunicação tem indubitáveis correspondências com a cultura organizacional, pois é a comunicação que veicula e consolida o conjunto de valores e pressupostos que constituem a cultura da organização. Diante dessa interface entre poder, comunicação e cultura, e diante do fato de o poder, por meio das estruturas hierárquicas formais, interferir não só na hierarquia, mas também na linguagem, podendo levar tanto ao silenciamento quanto ao diálogo entre os atores organizacionais, faz-se necessário analisar os motivos que subjazem à interdição da fala e as vantagens de uma gestão fundada na comunicação e no diálogo. 
É necessário que os executivos reconheçam o poder da linguagem, já que dois terços de sua atividade profissional é ocupada por ela. Relativamente à importância da fala - uma das faculdades da linguagem expressa por palavras - nas organizações, Sidinéia Gomes Freitas afirma:

"Apesar de certa obviedade decorrente da inegável importância do uso da palavra falada e seu peso nas relações interpessoais, pouco os executivos sabem a respeito do uso da palavra e do lugar que a fala ocupa na vida dos homens" (FREITAS, 2006, p. 145).

Além disso, é por meio da linguagem, falada ou escrita, que se constroem as representações da realidade e as visões de mundo de uma época, de uma sociedade ou de uma organização (GUERRA, 2006, p. 158). Por essa razão, "a palavra e, em especial, a fala, torna-se o instrumento por excelência da ação do executivo, o meio essencial para entrar em contato com os outros, e para obter resultados" (CHANLAT; BÉDARD, 2007, p. 126). No entanto, no mundo do trabalho e no acadêmico, a interdição da fala é uma constante e ocorre supostamente em prol da eficiência e eficácia, nas organizações, e da cientificidade, na academia, e tem como principal consequência a interdição do diálogo do outro. Além disso, a interdição da fala nas organizações desmascara o discurso de incentivo à mudança e à participação. Outra consequência desse silenciamento compulsório é o fortalecimento dos canais informais de comunicação, onipresentes em toda e qualquer organização, como, por exemplo, a rádio peão ou rádio corredor. Aliás, o surgimento dos grupos informais é um indício mais do que evidente da profunda violência que representa a interdição à fala. Para Chanlat e Bédard (2007), esses grupos, caracterizados pela metacomunicação, constituem um exemplo a ser seguido pelas estruturas formais da organização, já que cada um de seus integrantes busca sentir-se um indivíduo e ver no olhar de seu interlocutor a confirmação de sua importância, ou seja, busca o prazer de poder falar e de poder ser ouvido.

Muitos são os empecilhos ao diálogo nas organizações. Dentre eles, podemos citar: a inveja, o individualismo, a hierarquização, as disputas de poder, a rapidez, fruto da obsessão pela eficiência/ eficácia etc. O imediatismo, aliás, é um poderoso impedimento ao diálogo que requer conversação e, portanto, consome tempo. Relativamente à primazia da administração do tempo no Ocidente, Chanlat e Bédard fazem a seguinte afirmação:

"É quando se entra em contato comercial com outras pessoas, de outras culturas, ainda respeitadoras dos rituais básicos das conversas, que se descobre a grosseria de muitos contatos profissionais no Ocidente, e que se coloca em questão o valor da eficácia associada à rapidez. Talvez seja uma das lições mais interessantes que o Japão nos tenha ensinado; o segredo do sucesso de um dirigente reside na arte de saber perder o tempo, para ganhá-lo" (CHANLAT; BÉDARD, 2007, p. 138). 
As disputas de poder também constituem um forte obstáculo ao diálogo, pois os que tentam buscar o poder na maioria das vezes assumem uma atitude de avareza em relação à palavra, sobretudo quando se encontram nos grupos informais, e, com esse comportamento, "reforçam o discurso oficial que cria obstáculos ao diálogo” (FREITAS, 2006, p. 146). A avareza em relação à palavra também indica obediência e submissão, já que os dogmas administrativos da autoridade, da racionalidade e da disciplina levam à institucionalização do monólogo e à autocensura dos empregados. Chanlat e Bédard ressaltam o antiintelectualismo do silenciamento compulsório:

"É espantoso notar, no contexto da administração, quanto os executivos vivem num universo de certeza, com a impressão de detentores da verdade. Isso lhes confere um baixo nível de tolerância à contestação e ao espírito crítico, e explica por que se fascinam pela miragem das explicações simplistas e reducionistas" (CHANLAT; BÉDARD, 2007, p. 138).

Mas o maior dos empecilhos é o relacionamento interpessoal. Há pessoas que não desejam o diálogo, somente a discussão e o debate que pressupõem a disputa, a competitividade, a racionalidade, a defesa de pressuposições e as justificativas. O debate e a discussão, tão frequentes nas organizações, valem-se da persuasão, ao passo que os elementos centrais do diálogo são os significados compartilhados e as lideranças participativas.

Ao comparar o diálogo e o debate, na obra Comunicação humana, Adler e Rodman (2003) estabelecem as seguintes diferenças entre ambos: a) o diálogo é colaborativo; o debate, oposicional; b) no diálogo, a meta é buscar uma base comum; no debate, a meta é ganhar; c) o diálogo amplia a visão dos participantes e possibilita mudanças de seus pontos de vista; o debate roforça os pontos de vista do debatedor; d) o diálogo possibilita a reavaliação das suposições; o debate defende obstinadamente as suposições do debatedor; e) o diálogo faz com que os participantes pensem sobre os pontos de vista de seus interlocutores; o debate faz com que os participantes critiquem as posições de seus interlocutores; f) o diálogo favorece o encontro de novas e originais soluções; o debate exclui outras abordagens, privilegiando as posições do debatedor; g) no diálogo, existe a preocupação de não ofender o(s) interlocutor(es); no debate, o interlocutor é retaliado, diminuído ou depreciado e não há qualquer preocupação por parte do debatedor com os sentimentos do outro ou com os relacionamentos existentes.

Ellionor e Gerard (1998) afirmam que o diálogo é uma poderosa prática de comunicação e liderança, capaz de transformar os atores que nela se deixam envolver e, por consequência, a cultura organizacional na qual se encontram inseridos. Segundo as autoras, o diálogo é um poderoso agente de transformação, porque envolve três importantes aspectos da vida organizacional: a) a comunicação em geral; b) o desenvolvimento de líderes; c) a modificação da estrutura organizacional. Se isso já não bastasse, o diálogo ainda dá outra dimensão ao trabalho, substituindo as práticas tradicionais de gerência competitiva pela cultura de colaboração e parceria entre os atores organizacionais. 
O diálogo faz-se presente nos locais onde se valoriza a construção de relacionamentos, a criatividade e a recusa de conflitos. É sabido que líderes com habilidades técnicas, mas sem habilidades para perceber, entender e influenciar as emoções de seus subordinados, têm maiores dificuldades de encontrar quem queira trabalhar com eles. Para o líder tecnicamente hábil, mas com pouca inteligência emocional, há três saídas possíveis: a) mudar de emprego, o que significa transferir o mesmo padrão de comportamento para outro local de trabalho; b) modificar suas tarefas de tal forma que dependam mais de suas habilidades técnicas; c) desenvolver as habilidades que lhe faltam, ou seja, aprender a relacionar-se bem com seus subordinados e seus pares, exercendo a prática do diálogo.

Ao longo do tempo, a prática do diálogo favorece o surgimento de níveis mais elevados de autenticidade, a melhoria das decisões, do moral e do alinhamento em torno do trabalho compartilhado. No entanto, ainda há uma total falta de conscientização e uma grande confusão por parte dos gestores em relação às finalidades do trabalho e, consequentemente, à importância do diálogo nas organizações. Os gestores ainda se encontram muito presos a sistemas de valores, normas e crenças baseados na cultura da racionalidade, da produtividade e do lucro, cultura que os desviam de relacionamentos satisfatórios e de um trabalho mais significativo. Esse apego à cultura do resultado e do lucro leva a uma crise de significados que somente será superada com a implantação de outro tipo de cultura: a cultura do compartilhamento e do diálogo.

Segundo Ellionor e Gerard (1998), faz-se necessário mesclar os antigos (visão newtoniana) e os novos modos (visão quântica) de organizar e gerenciar as organizações. O modelo mecânico de organização partia dos seguintes pressupostos:

a) as organizações têm uma estrutura hierárquica e funcionam como máquinas cujas peças são removíveis e facilmente substituíveis (os empregados);

b) os líderes são capitães que se encontram no leme de lentos navios.

O novo modelo de organização - no qual a informação e a comunicação intra e interdepartamental, bem como o diálogo, passaram a ser essenciais - requer uma nova orientação. Para as autoras, a constituição desse novo direcionamento deve basear-se nos seguintes princípios:

a) foco em relacionamento e processo e não em estruturas e tarefas;

b) substituição do poder e do controle pela liderança compartilhada;

c) substituição da fragmentação pela visão holística;

d) conscientização de que há muitas respostas certas em vez de uma única resposta certa;

e) busca do significado compartilhado e do consenso em vez de decisões de cima para baixo; 
f) substituição da competição pela colaboração;

g) valorização do domínio coletivo em detrimento do autodomínio;

h) alavancagem da diversidade;

i) valorização do pensamento sistêmico em lugar do pensamento linear;

j) suspensão dos julgamentos;

k) suspensão das suposições;

l) prática do questionamento e da reflexão.

Para essas autoras, a suspensão dos julgamentos e das suposições, ou seja, o silenciamento do eu, é condição sine qua non para que o diálogo possa se estabelecer.

Ainda segundo Ellionor e Gerard (1998), a urgência da mudança de orientação organizacional com base na comunicação e no diálogo deve-se, sobretudo, aos desafios do mundo contemporâneo, caracterizado, entre outras coisas, pela rapidez das mudanças, pela complexidade da realidade, pela alienação da força de trabalho, fruto da ausência de significado e motivação, pela integração da diversidade e por um ininterrupto gerenciamento de crises. As autoras ressaltam, no entanto, que o novo modelo organizacional, orientado para a comunicação e o diálogo, deve mesclar-se ao modelo newtoniano, uma vez que não se podem abandonar por completo elementos como hierarquia e tomada de decisões.

\section{Considerações finais}

Como vimos ao longo deste artigo, desde a época das sociedades tribais, o homem busca o poder, luta pela dominação e, ao mesmo tempo, submete-se às mais diversas formas de poder. No mundo organizacional, no qual os poderes financeiro, normativo e coercitivo estão presentes desde sempre, o exercício e a sujeição do indivíduo ao poder tornam-se ainda mais evidentes. No entanto, o poder gera o contrapoder e, por essa razão, não pode ser único e absoluto, tampouco assegurado ao líder, sobretudo num mundo globalizado e tecnológico no qual a precipitação das mudanças e a complexidade da realidade demandam novas formas de relações de poder, fundadas especialmente na comunicação, no diálogo e na gestão participativa, compatível com os novos paradigmas.

O diálogo é, portanto, o meio de se chegar ao novo modelo organizacional marcado pelo significado compartilhado e pela liderança participativa. Vimos aqui que, além de constituir um poderoso fator de transformação, o diálogo remete à busca por novos significados e está em consonância com os novos tempos que, por sua vez, demandam novas relações de poder. Portanto, seria mais proveitoso que os líderes, detentores do poder nas organizações, dessem mais importância tanto ao aprimoramento da linguagem quanto a sua relevância no mundo organizacional e que transformassem o diálogo numa estratégia para criar um mundo mais humano e sustentável. 


\section{Referências}

ADLER, Ronald B.; RODMAN, George. Comunicação humana. Rio de Janeiro: LTC, 2003.

CHANLAT, Alain; BÉDARD, Renée. Palavras: a ferramenta do executivo. In: CHANLAT, Jean-François et al. 0 indivíduo na organização - dimensões esquecidas. São Paulo: Atlas, 2007. p. 125-148.

CLEGG, Stewart. Poder, linguagem e ação nas organizações. In: CHANLAT, Jean-François et al. 0 indivíduo na organização dimensões esquecidas. São Paulo: Atlas, 2007. p. 47-66.

ELLIONOR, Linda; GERARD, Glenna. Diálogo: redescobrindo o poder transformardor da conversa. São Paulo: Futura, 1998.

FREITAS, Leandro. Comunicação interpessoal face-a-face: uma forma de poder nas organizações privadas. Monografia de especialização. São Paulo: Escola de Comunicação e Artes da Universidade de São Paulo, 2005. Disponível em: <http:// gestcorp.incubadora.fapesp.br/portal/monografias/index2>. Acesso em 13 jan. 2008.

FREITAS, Maria Ester de. Cultura organizacional. São Paulo: Thomson Learning, 2007.

FREITAS, Sidinéia Gomes. Liderança e poder: um enfoque comunicacional. In: MARCHIORI, Marlene. Faces da cultura e da comunicação organizacional. São Caetano do Sul: Difusão Editora, 2006. p. 135-148.

. Comunicação, poder e cultura organizacional. Disponível em: <www.portal-rp.com.br/bibliotecavirtual/culturaor ganizacional/0105.htm>. Acesso em 12 jan. 2008.

GUERRA, Maria José. Contribuições da teoria linguística à abordagem da cultura e comunicação organizacional. In: MARCHIORI, Marlene. Faces da cultura e da comunicação organizacional. São Caetano do Sul: Difusão Editora, 2006. p. 149-163.

ROBBINS, Stephen P. Comportamento organizacional. São Paulo: Pearson Prentice Hall, 2005.

TORQUATO, Gaudêncio. Tratado de comunicação organizacional e política. São Paulo: Thomson Learning, 2004. 
